\title{
CONFERENCE REPORT 6th ANNUAL CONFERENCE OF REHABILITATION ENGINEERING
}

San Diego, California, was the site for the Annual Conference in June I983 of the Rehabilitation Engineering Society of North America. Several hundred engineers, therapists, manufacturers and disabled people met to hear nearly 300 papers on communication aids and control interfaces, microprocessor systems, neuromuscular electrical stimulation, seating and positioning, and other uses of technology for the disabled. There were also extended workshops on standardisation and international collaboration. At luncheon seminars, recognised authorities on a dozen different topics chaired round table discussions with small groups and there was ample time during the conference for informal meetings. There were also demonstrations of techniques such as computer controlled walking and products such as Ultralite aircraft for paraplegics. About one hundred commercial and university exhibitors showed products ranging from mouthsticks to voice controlled word processors to wheelchairs which moved sideways and climbed stairs.

Notable features of the Conference were the acceptance of commercial manufacturers as peers and the presence of representatives of Government and other funding agencies, who took part in seminars on priorities for funding and the preparation of grant applications. The next Annual Conference, the 7 th, is to be held in Ottawa from 17-22 June 1984 in association with the 2 nd International Conference on Rehabilitation Engineering. There will be special sessions on implant materials and devices, communication aids, prosthetics and orthotics, neural prostheses, and spinal cord rehabilitation. In addition to paper and poster sessions, there is a student design competition and commercial and scientific exhibits. There are also one and two day instructional courses on ten topics such as seating and positioning, computerised aids for the handicapped, robotics, gait analysis, technology transfer and grant applications. The secretariat address is:

2nd ICRE,

c/o National Research Council of Canada,

Ottawa,

Ontario,

Canada Kr A OR6.

Mr G. H. Creasey, F.R.C.S.E., Spinal Unit, Edenhall Hospital, Musselburgh, Scotland. 